\section{$\underset{\substack{\text { hommes } \\ \text { \& migrations }}}{ }$}

\section{Hommes \& migrations}

Revue française de référence sur les dynamiques

migratoires

$1284 \mid 2010$

Migrations et environnement

\title{
Le violon d'un horticulteur mélomane venu de Bohême
}

Fabrice Grognet

\section{OpenEdition}

\section{Journals}

Édition électronique

URL : http://journals.openedition.org/hommesmigrations/1261

DOI : 10.4000/hommesmigrations.1261

ISSN : 2262-3353

Éditeur

Musée national de l'histoire de l'immigration

Édition imprimée

Date de publication : 1 mars 2010

Pagination : 158-162

ISSN : 1142-852X

Référence électronique

Fabrice Grognet, «Le violon d'un horticulteur mélomane venu de Bohême », Hommes \& migrations [En ligne], 1284 | 2010, mis en ligne le 29 mai 2013, consulté le 22 septembre 2020. URL : http:// journals.openedition.org/hommesmigrations/1261 ; DOI : https://doi.org/10.4000/ hommesmigrations.1261

Ce document a été généré automatiquement le 22 septembre 2020

Tous droits réservés 


\title{
Le violon d'un horticulteur mélomane venu de Bohême
}

\author{
Fabrice Grognet
}

“Jusqu'à la guerre, ma mère retournait tous les ans
dans sa famille et nous ramenait de merveilleux livres
de contes et d'histoires tchèques qu'elle nous lisait le
soir. Mon père, quant à lui, ne s'est rendu qu'une seule
fois dans la sienne, en 1956, pour une demi-journée. Se
sentant si misérablement étranger, il remonta dans sa
voiture... Pour la France, chez lui."
Édith Salzman, fille de François et Angèle Stursa.

Édith Salzman découvre la Cité nationale de l'histoire de l'immigration au moment de son ouverture, en octobre 2007 : “C'est la curiosité qui m'a amenée à la Cité. Initialement j'étais seulement venue voir ce musée de l'immigration. Mais après la visite, quand j'ai vu à l'accueil une boîte où l'on pouvait déposer une fiche pour proposer des dons, il m'a apparu évident que le violon de mon père représentait le mieux son pays, sa vie et finalement notre vie. Mon père a acheté ce violon à un saltimbanque de passage, parce qu'il a cet adage - qui m'est tombé dessus aussi - selon lequel 'tous les Tchèques naissent avec un violon dans les mains'. Résultat, à 8 ans, je suivais des cours de violon et lui apprenait le solfége avec moi. Car il ne jouait du violon qu'à l'oreille, comme un tsigane. Cela a rythmé notre vie, et cet instrument a aussi été un lien pour faire connaissance avec cette petite ville de Sainte-Ménehould où nous nous sommes établis. Et quand, après le décès de ma mère, j'ai quitté Sainte-Ménehould, c'est mon père qui a repris le pupitre jusqu'à la dissolution de l'orchestre philharmonique".

Instrument où figure au verso une sculpture de château des Carpates, ce violon, acheté en France à un "bohémien" de passage par un Tchèque immigré, est ainsi devenu, après le don d'Édith, le "témoin" de l'itinéraire de son père. 


\section{Le choix de partir}

3 Frantisèk Stursa naît le 3 décembre 1901 à Zajerice, en Bohême, au sein de l'Empire austro-hongrois. Au moment de choisir sa voie professionnelle, il s'oriente vers l'horticulture. Diplômé de l'École des jardins de la ville de Chrudim, Frantisèk décide, sur la foi de quelques recommandations, de quitter la jeune République tchécoslovaque pour la Suisse en 1920, afin de parfaire son enseignement à Sarnen, puis à Interlaken.

Quatre ans plus tard, Frantisèk part à nouveau, pour la France cette fois. Aussi, et comme le souligne sa fille Édith, "ce n'est ni la misère, ni la pauvreté, ni la fuite d'une guerre qui ont fait venir mon père en France. Orphelin très tôt de mère, les raisons de son exil sont plutôt d'ordre familial et liées à une curiosité du monde. Il est parti avec en tête l'idée de faire de l'horticulture. Il avait suivi des écoles en Tchécoslovaquie et, de bouche-à-oreille, il est passé par les meilleurs endroits, notamment en Suisse, où il a fait ses classes".

5 À ce moment, l'immigration tchèque est facilitée par la convention signée en 1920 entre la Tchécoslovaquie et la France, cette dernière recherchant de la main-d'œuvre pour son industrie. C'est ainsi que Frantisèk arrive en train au centre de Toul (Meurthe- etMoselle), où transitent les immigrés tchèques, puis passe deux mois dans les mines de fer de Lorraine, avant de trouver un emploi comme horticulteur à Thionville. C'est alors qu'il rencontre des compatriotes, horticulteurs eux aussi, qui fournissent les meilleures boutiques de fleuristes de Paris. Et si l'avenir de Frantisèk passait par la capitale française?

\section{De la gare de l'Est à Sainte-Ménehould}

Se faisant désormais appeler "François", Frantisèk part donc vers Paris en 1926 et trouve rapidement plusieurs emplois - souvent précaires - dans de grandes entreprises de fleuristes parisiens ${ }^{1}$, grâce à ses contacts dans les réseaux tchécoslovaques de la capitale.

7 C'est aussi à Paris que François rencontre Andela Volmanova, couturière tchèque née à Brandys nad Labem en 1905, qui compte rejoindre sa sœur aux Etats-Unis: "Un jour, mon père a accompagné un ami à la gare de l'Est qui venait chercher sa cousine venant de Prague. Et cette cousine, c'était celle qui allait devenir ma mère!"

Le 28 avril 1928, François et "Angèle2" se marient à Saint-Cloud. François devient alors "jardinier de château" en Gironde, où naît Édith, puis à Rambouillet, où naît sa seconde fille. La famille part s'installer en 1931 à Sainte-Ménehould, dans la Marne, où le paysage rappelle à François sa Bohême natale. Il y reprend une modeste entreprise maraîchère grâce à l'argent donné par l'oncle d'Angèle - Joseph Volmanova propriétaire d'une usine de machines-outils à Celakovice, près de Prague. À partir de ce moment, François, en tant que fleuriste, achalande les trois départements limitrophes en chrysanthèmes et autre cyclamens et participe à toutes les commémorations: "À l'inverse de mes camarades immigrés italiens, je n'ai pas eu de problème pendant mon enfance. Mon père étant propriétaire de son entreprise et participant aux événements rythmant la vie de la ville, nous n'avions pas un statut d'immigrés. Et puis 'Tchèques', cela ne signifiait pas grandchose pour la plupart des gens. Où était la Tchécoslovaquie? Par contre, avec l'amalgame Tchèques, Sudètes et 'boches', nous avons passé un sale quart d'heure: la Tchécoslovaquie n'était-ce pas un peu allemand?!" 


\section{Une guerre et deux engagements}

$9 \mathrm{Au}$ moment de la Seconde Guerre mondiale, François, toujours de nationalité tchécoslovaque après une demande de naturalisation infructueuse en 1938, s'engage, non pas dans les rangs de la "Légion étrangère", mais dans ceux de "l'Armée de libération tchécoslovaque" qui vient de se constituer en France ${ }^{4}$, grâce au soutien de l'ambassadeur Stefan Osusky (1889-1973).

10 Affecté au $1^{\mathrm{er}}$ régiment d'infanterie, après une instruction militaire à Agde, il connaît alors la "drôle de guerre" jusqu'à sa démobilisation, le 27 juin 1940, à Châlons-surMarne: "Quand l'affiche de la Mobilisation générale apparut au coin de notre rue SainteCatherine, mon père s'enrôla sur le champ et il se débrouilla pour rejoindre les rangs de l'Armée tchèque à l'étranger. Il a donc fait sa guerre comme tout le monde. Il a été démobilisé, comme tout le monde, et on a passé les temps de guerre, comme tout le monde, dans cette zone à la limite de ce qui était annexé et de ce qui était occupé. Ce qui nous sauva des amalgames hâtifs, c'est que nous résidions depuis plus de dix ans dans ce petit coin de France où mes parents étaient estimés."

11 De retour en Argonne, François entame alors une "autre" guerre, dans une vigilante et pragmatique discrétion "d'éternel étranger". Profitant de sa connaissance de la langue allemande et de sa relation fortuite avec un "enrôlé bulgare" de la Kommandantur, il détourne une part des légumes réquisitionnés par l'occupant pour les distribuer aux plus nécessiteux en cette période de disette : “À l'enterrement de mon père, une sœur de St Charles, économe de l'Hôpital, est venue. C'était pour le remercier de ce qu'il avait fait pendant la guerre. La forêt d'Argonne était en effet propice pour des rencontres nocturnes, toujours tues, donc inexistantes pour les non-concernés."

\section{Français avant d'être français}

12 À bien des égards, "mon père se sentait français avant d'être français. Avec mes parents, quelque chose de tchécoslovaque est passé à Sainte-Ménehould. Mais ils ont adopté ce pays comme si c'était le leur. À la maison, il n'y eut jamais de relations communautaires suivies, même si j'ai entendu mes premiers mots de français à trois ans, lorsque je suis entrée en maternelle à Sainte-Ménehould. Notre voisinage, nos relations avec la vie de cette bourgade argonnaise connue depuis que Jean-Baptiste Drouet, maître des postes à Sainte-Ménehould, a fait arrêter Louis XVI et sa famille à Varenne, suffisaient à notre existence."

13 C'est d'ailleurs à l'occasion d'une commémoration de ce fait historique que, dans l'immédiat avant-guerre, la famille Stursa connaît un "petit triomphe" dans les rues de sa ville d'adoption, comme l'évoque Edith : "Ma mère avait confectionné une robe à panier et notre voisine Léonie, chez qui j'apprenais le français et que je surnommais 'maman Nini', m'avait prêté un fichu en dentelle de Valencienne sur lequel mon père avait épinglé sa plus belle rose Meillant. Ainsi parée en Marie-Antoinette, comme toutes les petites filles de Sainte Ménehould, on me fit sortir du rang pour m'amener en tête de cortège, au bras du fils de la directrice d'école habillé, comme tous les petits garçons, en Louis XVI, et reléguant ainsi les filles du maire au second rang. Le 'Milanais', quartier à dominante immigrée - Italiens et Espagnols surtout - que nous habitions frémit de plaisir au passage de la fille du violoneux de Bohême ouvrant la marche avec la République de Jules Ferry." 
14 En 1953, François, ancien combattant, obtient sa naturalisation, range son violon et se remarie avec sa seconde épouse rencontrée, ironie du sort, à la gare de l'Est. Et à la mort de François Stursa, en 1968, c'est un hommage unanime qui salue la mémoire de l'“honnête et affable [...] jardinier-horticulteur de la rue Sainte-Catherine, [qui] était très connu tant dans la cité que dans la région argonnaise où il comptait de nombreux clients et amis et où il était très estimé" ("Le décès de M. Stursa", L'Est Républicain).

\section{NOTES}

1. Bauman et Lachaume notamment.

2. Anděla fait franciser son prénom.

3. Pour Frantisèk, la Légion était "l'école des brigands", alors que l'Armée de libération tchécoslovaque était "la route normale à suivre".

4. En mars 1939, la disparition de la Tchécoslovaquie provoque l'afflux en France de 6000 réfugiés. En septembre, après la déclaration de guerre, les hommes valides intègrent l'armée tchécoslovaque.

\section{AUTEUR}

\section{FABRICE GROGNET}

Ethnologue, chargé de mission au Musée national de l'histoire et des cultures de l'immigration, $\mathrm{CNHI}$ 